\title{
Geologists call time on dating dispute
}

\section{LONDON}

After more than 150 years of conflict, geologists have taken a small step towards agreeing what to call the time we live in.

The fight concerns time rather than space, yet feelings are running as high as in any border dispute. Supporters of one geological term have been accused of "expansionist tendencies" in their bid to annex neighbouring territory. They, on the other hand, say that their rivals are dinging to meaningless traditions of the past.

As the allegations fly, representatives of both sides voted on the issue last week in the first move towards a solution. But agreeing the details is likely to take months, if not years.

Since at least the nineteenth century, different groups of geologists have used conflicting terms to describe the recent past. Some simply describe the past 23 million years as the Neogene period. But others invoke an extra period - the Quaternary - which follows the Neogene and began around 2 million years ago.

The row has recently escalated, as a result of a seven-year international project that was meant to resolve such arguments. This involved finding and dating deposits around the world that mark transitions between periods, such as the appearance of a new type of rock, or the emergence of a new species in the local fossil record. The results were published last year, along with a definitive geological timescale (see Nature 429, 124-125; 2004).

But as the scale was being developed, Quaternary researchers learnt that their period had disappeared — absorbed by the Neogene. The result was a lot of angry geologists. ${ }^{\text {“ They tried }}$ to do away with it without anyone noticing," says Philip Gibbard, a Quaternary researcher at the University of Cambridge, UK. "I get an e-mail a day complaining about it."

Gibbard and his colleagues have since campaigned hard for the period to be restored. They say that there are clear geological records, such as evidence for an increase in the number of icebergs and glaciers, that mark the beginning of the Quaternary, and that the period has a unique identity, characterized by periods of glaciation and the emergence of humans.

The campaigners say that the fight is about more than just a name: if the term is removed from the time scale, they fear that their field

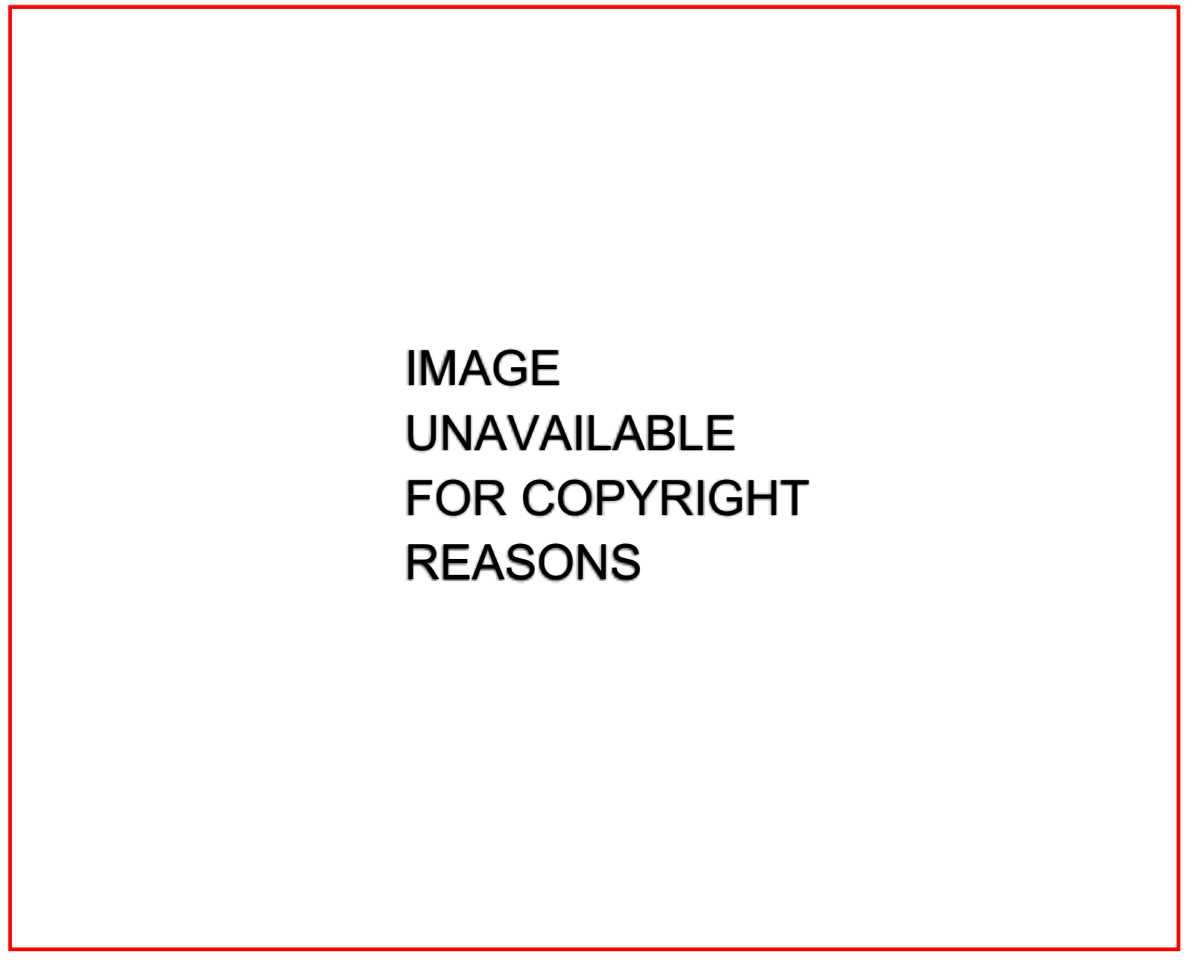

Period piece: glaciers are cited by some researchers as key evidence for a divisionin geological time.

could lose its identity and be deprived of the status it is due. "Thousands of scientists identify with this period," says Gibbard. "They do not take lightly to being labelled Neogene researchers." The term is certainly embedded in the research community; it appears in the name of at least seven societies and four journals around the world.

Those behind the latest timescale admit that the process could have been handled better. "I understand why they got angry," says Felix Gradstein of the University of Oslo, lead author of the timescale. "I apologize."

But behind his conciliatory tone lies an insistence that the Quaternary researchers do not have enough evidence to daim ownership of a separate period.

Gradstein and others argue that cooling events occurred several times during the past 60 million years and so are not suitable markers for a new period. They also point to the Quaternary community's long-standing disagreement over exactly when the period

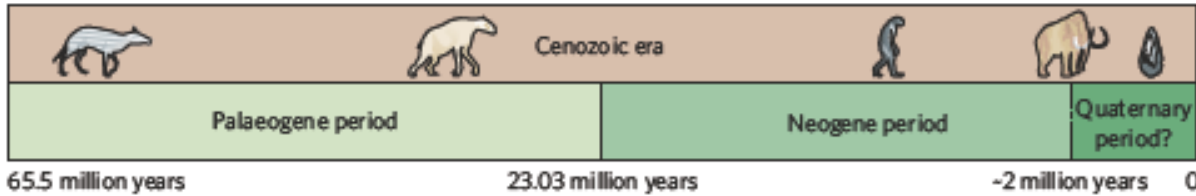

begins, and the fact that the Quaternary is a hangover from a previous naming system, the rest of which has been discarded.

And they seem to have had enough when it comes to allegations of expansionism. "I have seen a lot of nonsense from some hot-tempered colleagues," says Gradstein.

But a resolution might finally be in sight. An eight-member task force, set up last August by the International Commission on Stratigraphy (ICS), the organization that coordinated the timescale, and the International Union for Quaternary Research, voted last week to retain the name Quaternary in some form, and to define its onset as 2.6 million years ago.

It is now that the hard work really begins, says panel secretary James Ogg of Purdue University in West Lafayette, Indiana. Task-force members have to decide how to rank the Quaternary and will present their results to an ICS meeting this September in Leuven, Belgium. Should it remain a period or be downgraded to a subperiod? Or perhaps be removed officially from the hierarchy of the time series, but retained as an informal unit? "None of these will make everyone happy," warns Ogg. "Of course, the issue could be left undecided for another decade..."

Jim Giles 